\title{
RANCANG BANGUN MONITORING KUALITAS DAYA DENGAN RASPBERRY
}

\author{
Fahmi Islami Su'ud \\ Jurusan Teknik Elektro - Fakultas Teknik - UNIVERSITAS PAMULANG \\ Jln. Puspiptek Raya No 11 Buaran, Tangerang Selatan 15310 INDONESIA \\ E-mail: dosen01504@unpam.ac.id
}

\begin{abstract}
ABSTRAK
Kualitas daya mempunyai peranan penting baik dalam pengunaannya di masyarakat maupun dalam dunia industri. Dalam dunia industri umumnya menggunakan listrik 3 fasa untuk menggerakkan alat-alat elektronik dan mesin. Listrik 3 fasa peka terhadap perubahan tegangan yang mana dapat mengakibatkan rusaknya peralatan listrik. Agar kualitas daya tercapai, maka diperlukan monitor listrik 3 fasa ini. Pada penelitian ini telah dibuat sistem monitoring kualitas daya secara online yang dapat diakses melalui situs web. Parameter yang dapat dimonitor yakni arus, tegangan dan daya. Alat yang telah dibuat ini mampu melakukan pengukuran perubahan kualitas daya (dimana tegangan yang tidak tetap) dan ditampilkan di situs web secara real time yakni 1 detik melalui antar muka antara raspberry dengan sensor. Hasil pengujian sensor dimana dibandingkan dengan pengukuran alat ukur manual, didapatkan standar error pengukuran tegangan 0.45 , standar error pengukuran arus 0.24. Dari hasil pengukuran ini menunjukkan bahwa alat yang telah dibuat mempunyai nilai keakuratan sesuai standar IEC No. 13B-23.
\end{abstract}

Kata kunci: 3 fasa, sensor, SCT 013, trafo, raspberry, Website, IEC No. 13B-23

\begin{abstract}
Power quality has an important use both in society and industry. In the industry generally uses 3 phase electricity to drive electronic equipment and machinery. 3 phase electricity is sensitive to voltage changes which may cause damage to electrical equipment. In order to achieve the power quality, a 3-phase power monitor is required. In this research, an online power quality monitoring system has been built and can be accessed through the website. Parameters that can be monitored are current, voltage and power. The tool has been made is capable of measuring changes in power quality (where voltage is not fixed) and displayed on the website in real time about 1 second through the interface between raspberry and sensor. The result of the sensor test which was compared with the measurement of manual measuring instrument, the standard error of voltage measurement was 0.45 , while standard error for current measurement was 0.24 . From the results of this measurement indicates that the tool has accuracy value as according to IEC standard no. $13 B-23$.
\end{abstract}

Keywords: 3 phase, sensor, SCT 013, transformer, raspberry, Website, IEC No. 13B-23 


\section{PENDAHULUAN}

Daya listrik yang dikirimkan oleh utilitas kepada konsumen mempunyai kualitas yang baik apabila nilai dari tegangan dan frekuensinya sama atau sesuai dengan ketentuan yang berlaku yakni dalam sistem penyediaan tenaga listrik, dititik suplai diijinkan bervariasi $(+5 \%)$ dan $(-10 \%)$ sesuai standar PLN sedangkan dalam ANSI C 84.1 diijinkan ($10 \%)$ dan $(+4 \%)$ dalam kondisi normal sedangkan kondisi tertentu (darurat) diijinkan (-13\%) dan (+6\%). Apabila nilai tersebut tidak dipenuhi, maka kualitas daya listriknya berkurang dan dapat menyebabkan berbagai gangguan. Pada dunia industri, kualitas pasokan daya listrik berperan sangat penting karena memiliki dampak langsung pada operasi mesinmesin produksi serta efektifitas dan efisiensi proses produksi.

Baik buruknya sistem penyaluran dan distribusi tenaga listrik dipegaruhi oleh kualitas daya yang diterima oleh konsumen. Kualitas Daya yang baik antara lain meliputi kapasitas daya yang memenuhi kebutuhan dan tegangan yang selalu konstan. Tegangan harus selalu di jaga konstan, terutama rugi tegangan yang terjadi di ujung saluran. Tegangan yang tidak stabil dapat berakibat merusak alatalat yang peka terhadap perubahan tegangan (khususnya alat-alat elektronik). Demikian juga tegangan yang terlalu rendah akan mengakibatkan alat-alat listrik tidak dapat beroperasi dengan baik. Untuk monitor adanya perubahan tegangan ini, umumnya dilakukan pengukuran dengan alat ukur secara berkala. Namun terdapat kendala dimana jika pengukuran tersebut terabaikan karena tidak ada teknisi yang melakukan pengukuran. Hal ini menjadi tidak efektif dan efisien dalam menjaga kualitas daya jika dilakukan secara manual. Berdasarkan latar belakang tersebut, maka pada penelitian ini telah dibuat sistem monitoring kualitas daya menggunakan raspberry dan sensor-sensor terkait arus dan tegangan yang dikirim secara online dan ditampilkan di situs web.

\section{II.TEORI}

\subsection{Besaran Listrik}

Pada dunia kelistrikan, dikenal beberapa besaran listrik yang penting untuk diketahui, diantaranya adalah arus, tegangan dan daya. Arus listrik adalah banyaknya muatan yang mengalir pada sebuah penghantar dalam waktu satu detik (coulombs per second) yang diukur dalam satuan ampere (A).

Daya listrik adalah banyaknya energi listrik yang mengalir setiap detik atau joule per second yang diukur dalam satuan watt (W). Sedang Energi listrik dapat juga didefinisikan sebagai laju penggunaan daya listrik dikalikan dengan selama waktu tersebut. Satuan SI untuk energi listrik adalah Joule (J), namun dalam kehidupan sehari hari lebih dikenal dengan kilo watt hour $(\mathrm{kWh})$

Selanjutnya hubungan arus, tegangan dan daya dijelaskan dengan persamaan berikut:

$$
\begin{aligned}
& \mathbf{P}=\mathbf{V} . \mathbf{I} \\
& \mathbf{P}=\mathbf{I}^{\mathbf{2}} . \mathbf{R}
\end{aligned}
$$

Pada jaringan listrik AC dengan bentuk gelombang sinusoidal dikenal beberapa jenis bentuk daya, diantaranya adalah daya kompleks, daya aktif dan daya reaktif. Perkalian tegangan $\mathrm{V}$ dengan arus I* dalam kedua besaran ini dalam bentuk kompleks adalah VI* yang dinamakan daya 
kompleks dengan simbol S, dalam satuan Volt Ampere (VA).

Daya aktif atau daya nyata dirumuskan dengan $\mathrm{S} \cos \theta$ atau VI* $\cos \theta$ dengan simbol P, dalam satuan Watt (W). Sedangkan daya reaktif atau daya khayal dirumuskan dengan $\mathrm{S} \sin \theta$ atau VI* $\sin \theta$ dengan simbol $\mathrm{Q}$, dalam satuan Volt Ampere Reaktif (VAR). Hubungan antara ketiga jenis daya diatas dapat dijelaskan dengan sketsa segitiga daya seperti ditunjukkan pada Gambar 2.1 berikut:

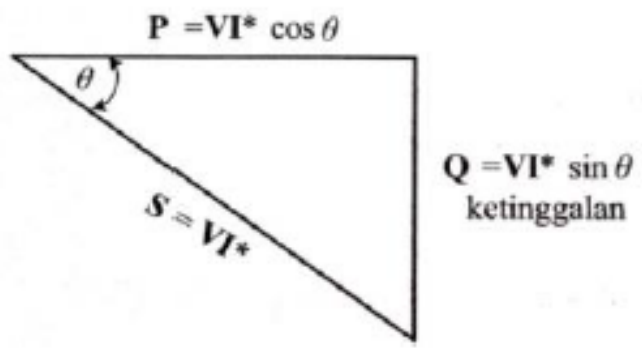

Bersifat induktif.

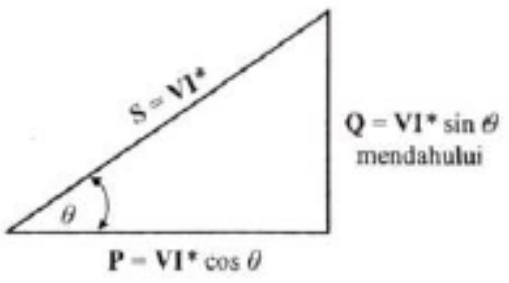

Bersifat kapasitif.

Gambar 2.1. Segitiga Daya

Komponen-komponen segitiga daya dapat dituliskan sebagai berikut:

Daya aktif : $\mathrm{P}=\mathrm{VI}^{*} \cos \theta(\mathrm{W})$

Daya reaktif : $\mathrm{Q}=\mathrm{VI}^{*} \sin \theta(\mathrm{VAR})$

Daya kompleks : $\mathrm{S}=\mathrm{VI} *(\mathrm{VA})$

Faktor daya : p.f $=\cos \theta$
Dengan adanya sudut fasa $\theta$ maka akan muncul sebuah besaran yang disebut Faktor daya atau power factor (p.f) yang merupakan nilai cosinus dari besar sudut fasa $\theta$.

\subsection{Pengukuran Tegangan Tinggi AC}

Untuk melakukan pengukuran tegangan tinggi AC, metode yang digunakan adalah dengan cara menurunkan tegangan tinggi ke tegangan rendah. Metode ini yang digunakan dalam pembuatan alat ukur tegangan atau Voltmeter. Untuk menurunkan tegangan dapat dilakukan dengan cara, yaitu dengan menggunakan rangkaian pembagi tegangan atau yang kedua dengan menggunakan transformator step down.

Transformator yang baik untuk digunakan sebagai sensor tegangan adalah transformator yang memiliki sifat linieritas yang baik.

\subsection{Pengukuran Arus AC}

Sensor arus adalah perangkat yang mendeteksi arus listrik (AC atau DC) di kawat, dan menghasilkan sinyal sebanding dengan itu. Sinyal yang dihasilkan bisa tegangan analog atau arus atau bahkan digital. Hal ini dapat kemudian digunakan untuk menampilkan arus yang akan diukur dalam ammeter atau dapat disimpan untuk analisis lebih lanjut dalam sistem akuisisi data atau dapat dimanfaatkan untuk tujuan kontrol. Sensor arus yang digunakan adalah SCT 013. Sensor arus ini sangat berguna untuk mengukur arus bolak-balik dari kabel 
R,S,T. SCT 013 sensor saat ini dapat mengukur hingga 100A arus AC.

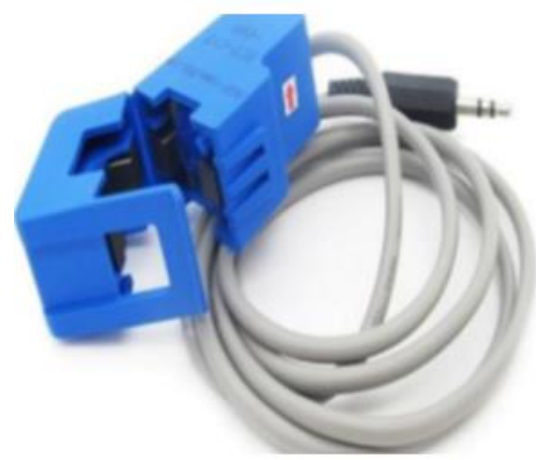

Gambar 2.2. Sensor Sct 013-000

\subsection{Raspberry pi 3 B}

Raspberry pi atau sering disingkat dengan nama Raspi, adalah komputer papan tunggal (single-board circuit; SBC) yang seukuran dengan kartu kredit yang dapat digunakan untuk menjalankan program. Raspi dikembangkan oleh yayasan nirlaba, Rasberry Pi Foundation. Raspi mempunyai beberapa varian, salah satunya raspberry pi $3 \mathrm{~B}$. Dimana jenis raspberry ini memiliki fitur yang cukup lengkap. Jenis mikrokomputer ini memiliki 1 GB Ram, 40pin extended GPIO, BCM43143 WiFi on board.

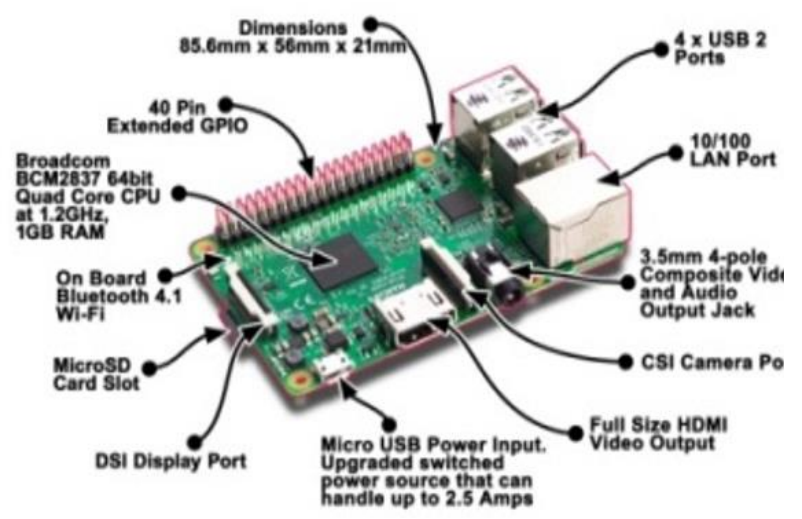

Gambar 2.3. Raspberry Pi 3

\subsection{Arduino Nano}

Arduini nano adalah papan pengembangan (development board) mikrokontroler yang berbasis chip ATmega328P dengan bentuk yang sangat kecil. Secara fungsi tidak ada bedanya dengan Arduino Uno. Perbedaan utama terletak pada ketiadaan jack power DC dan penggunaan konektor Mini-B USB. Disebut sebagai papan pengembangan karena board ini memang berfungsi sebagai arena prototyping sirkuit mikrokontroller. Chip ATmega328 yang terdapat pada Arduino Nano telah diisi program awal yang sering disebut bootloader. Chip ATmega328 pada Arduino Uno R3 memiliki memori $32 \mathrm{~KB}$, dengan $0.5 \mathrm{~KB}$ dari memori tersebut telah digunakan untuk bootloader. Jumlah SRAM $2 \mathrm{~KB}$, dan EEPROM $1 \mathrm{~KB}$, yang dapat di baca-tulis dengan menggunakan EEPROM library saat melakukan pemrograman. Arduino Nano memiliki 14 buah digital pin yang dapat digunakan sebagai input atau output dan bekerja pada tegangan $5 \mathrm{~V}$.

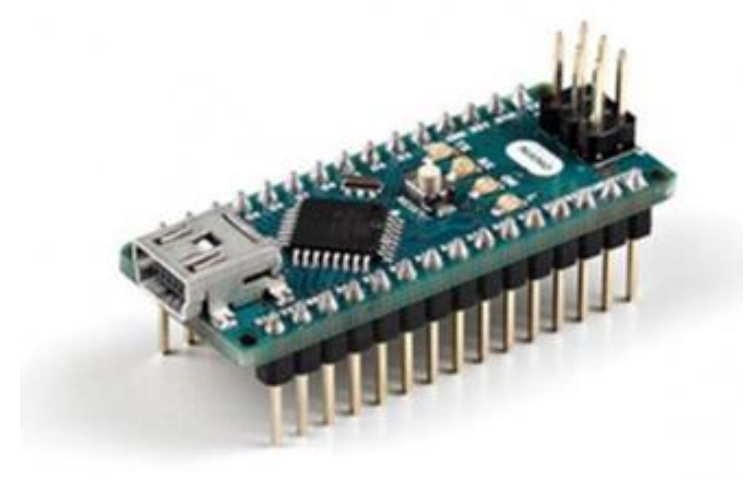

Gambar 2.4. Arduino Nano

\section{III.METODE PENELITIAN}

Langkah-langkah dalam Penelitian ini dapat dilihat pada gambar 3.1 dibawah ini. 


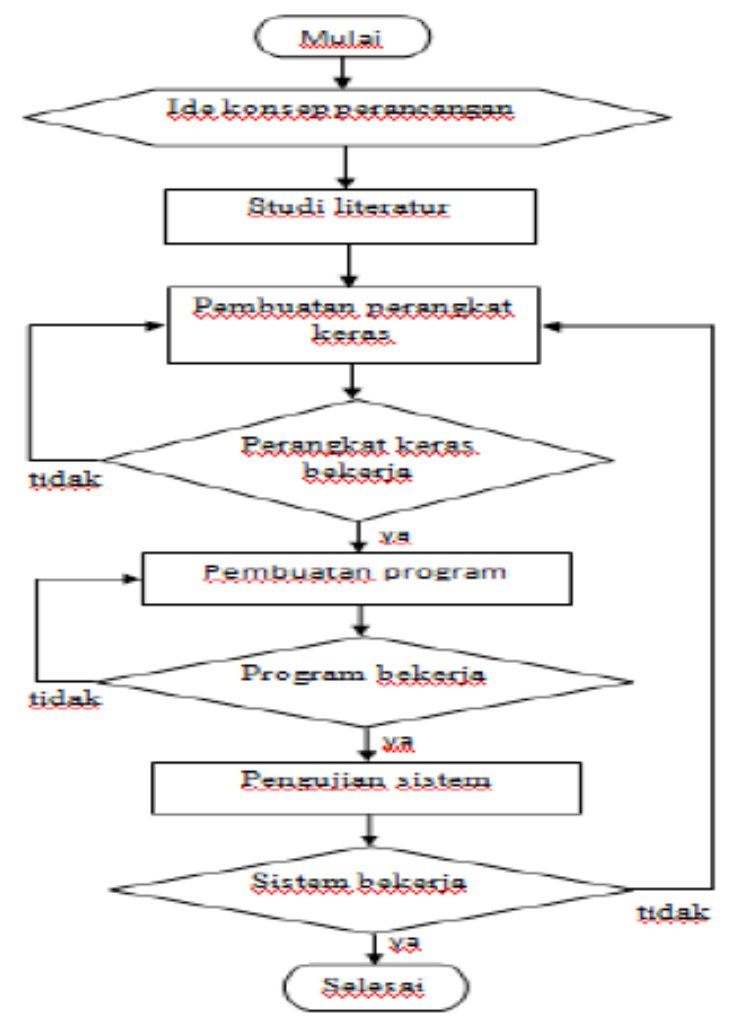

Gambar 3.1. Diagram Alir Penelitian

\subsection{Blok Diagram Sistem}

Untuk membuat sistem monitoring besaran listrik ini, alurnya adalah yang pertama dari sumber listrik 3 fasa masuk ke sensor arus dan sensor tegangan, selanjutnya dihubungkan ke beban listrik yang digunakan. Hasil pembacaan sensor arus dan sensor tegangan akan diolah oleh arduino untuk mendapatkan semua besaran listrik yang diinginkan. Selanjutnya data tersebut diproses oleh raspberry untuk dapat dikirim ke laptop melalui jaringan internet atau local area network dimana ditampilkan berupa situs web (website). Berikut ini blok diagram sistem yang terdiri beberapa bagian:

- Pengolah data: Raspberry dan Arduino

- Sensor: Sensor arus dan sensor tegangan

- Antarmuka user interface website: Laptop

Blok diagram sistem ditunjukkan pada Gambar 3.2 berikut:

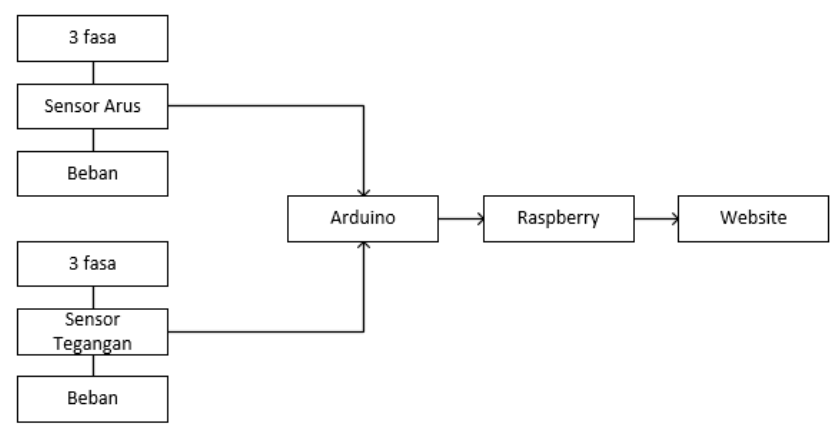

Gambar 3.2. Blok Diagram Sistem

\subsection{Perancangan Sistem}

Perancangan sistem dari penelitian ini meliputi:

A. Perancangan sensor tegangan dan sensor arus

Dalam perancangan sensor tegangan digunakan transformator stepdown untuk menurunkan tegangan dari level tegangan tinggi ke level tegangan rendah. Keluaran trafo masih berupa tegangan AC sehingga dibutuhkan rangkaian pengkondisian sinyal agar di dapat tegangan yang aman bagi Arduino.

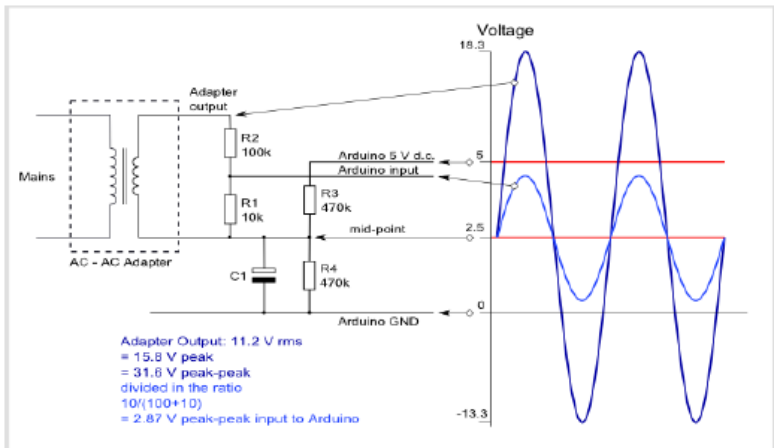

Gambar 3.3. Rangkaian Sensor Tegangan

Sensor arus menggunakan seri SCT-013 100A, sensor ini akan memberikan tegangan output yang linier dengan perubahan arus yang diukur. Sinyal keluaran SCT-013 100A tergantung sinyal masukan, jika arus yang diukur adalah arus AC maka sinyal keluaran merupakan sinyal $\mathrm{AC}$ dan jika arus yang diukur adalah arus 
DC maka sinyal keluaran merupakan sinyal DC. Pada penelitian ini arus yang akan diukur adalah arus AC sehingga perlu ditambahkan rangkaian pengkondisian sinyal agar aman bagi arduino. Rangkaian sensor arus yang akan dibuat ditunjukkan pada Gambar 3.4.

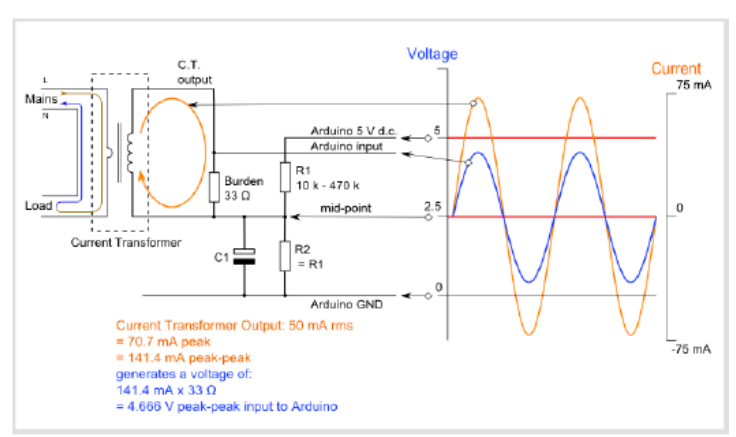

Gambar 3.4. Rangkaian Sensor Arus

B. Perancangan Perangkat Lunak

Pemrograman dilakukan dalam tahap ini meliputi:

- Pemrograman Arduino untuk pembacaan sensor

- Pemrograman python raspberry pi untuk mengolah data dan mengirim ke website

\subsection{Kalibrasi}

Dalam tahapan perancangan membutuhkan kesiapan alat ukur sebagai pembanding. Untuk menggunakan sebuah alat ukur digital persentase kesalahan haruslah kecil dan sensor-sensor yang digunakan harus sangat mendukung. Dalam penelitian ini digunakan alat tukur digital yang sudah ada menggunakan Digital Power Clamp Meter.

\section{IV.HASIL DAN PEMBAHASAN}

Pengujian sistem dilakukan pada bagian perangkat keras yakni uji fungsi rancangan sensor arus dan sensor tegangan sehingga dapat mengukur arus dan tegangan. Lalu pengujian pada kualitas daya yang dapat dimonitor dan kehandalan raspberry pi dalam mengolah data untuk mengirim data ke website.

\subsection{Pengujian Sensor Arus}

Pada pengujian sensor arus dilakukan dengan melakukan pengukuran manual dengan alat ukur sebagai pembanding, lalu melakukan pengukuran dengan sensor arus. Hasil dari keduanya dibandingkan sehingga dapat diketahui tingkat akurasi alat tersebut.

Sensor arus menggunakan seri SCT-013 100A, sensor ini akan memberikan tegangan output yang linier dengan perubahan arus yang diukur. Hasil pengujian rangkaian sensor arus sct 013 dapat dilihat pada tabel 4.1. Dalam penelitian ini pengujian dilakukan dengan beban motor $7.5 \mathrm{kw}$ pada mesin chiller yang di mainkan valvenya.

Tabel 4.1. Hasil Pengujian Rangkaian Sensor Arus

\begin{tabular}{|l|l|}
\hline $\begin{array}{c}\text { Arus } \\
(\mathrm{A})\end{array}$ & VDc Setelah Penguatan \\
\hline 0 & 0 \\
\hline 11 & 0.55 \\
\hline 11.5 & 0.525 \\
\hline 12 & 0.60 \\
\hline 12.5 & 0.625 \\
\hline 13 & 0.65 \\
\hline 13.5 & 0.675 \\
\hline 14 & 0.70 \\
\hline
\end{tabular}

Dalam tabel tersebut dapat dilihat bahwa pengujian pengukuran arus berhasil dilakukan dengan sensor sct-013 dimana menghasilkan keluaran VDc yang terbaca di Arduino.

Hasilnya menunjukkan semakin besar arus yang diukur, VDc juga semakin 
besar. Berikut tampilan dalam grafik pada gambar 4.1.

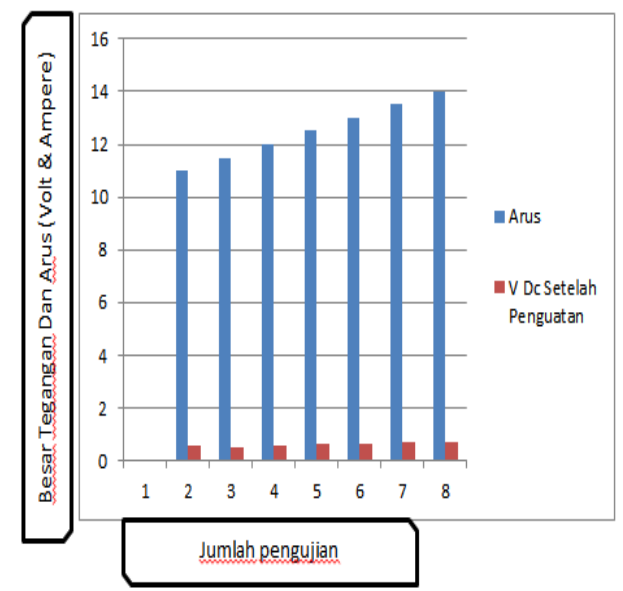

Gambar 4.1. Grafik Hasil Pengujian Sensor Arus

\subsection{Pengujian Sensor Tegangan}

Pada pengujian ini menggunakan motor $7.5 \mathrm{kw}$ sebagai bebannya dimana pengukuran dilakukan baik itu secara manual yaitu dengan menggunakan multitester dan dengan sensor tegangan. Pengukuran dilakukan sebanyak 12 kali untuk memperoleh tingkat akurasi datanya.

Tabel 4.2. Hasil Pengukuran Rangkaian Sensor Tegangan

\begin{tabular}{|l|l|l|}
\hline $\begin{array}{c}\text { Pengukuran } \\
\text { ke- }\end{array}$ & $\begin{array}{c}\text { V Out Trafo Step } \\
\text { Up 220 V }\end{array}$ & $\begin{array}{c}\text { V DcOut } \\
\text { Pembagi } \\
\text { Tegangan }\end{array}$ \\
\hline 1 & 300 & 3.66 \\
\hline 2 & 310 & 3.78 \\
\hline 3 & 320 & 3.9 \\
\hline 4 & 330 & 4.02 \\
\hline 5 & 340 & 4.14 \\
\hline 6 & 350 & 4.26 \\
\hline 7 & 360 & 4.38 \\
\hline 8 & 370 & 4.5 \\
\hline 9 & 380 & 4.62 \\
\hline 10 & 390 & 4.74 \\
\hline 11 & 400 & 4.86 \\
\hline 12 & 410 & 4.98 \\
\hline
\end{tabular}

Dari hasil pada tabel 4.2 diatas, sensor tegangan dapat bekerja dengan baik dimana mampu menyesuaikan nilainya sesuai dengan Vout Trafo. Semakin besar nilai tegangan pada trafo, nilai yang dibaca oleh sensor tegangan semakin besar. Berikut ini tampilan grafik konsistensi sensor tegangan terhadap Vout trafo.

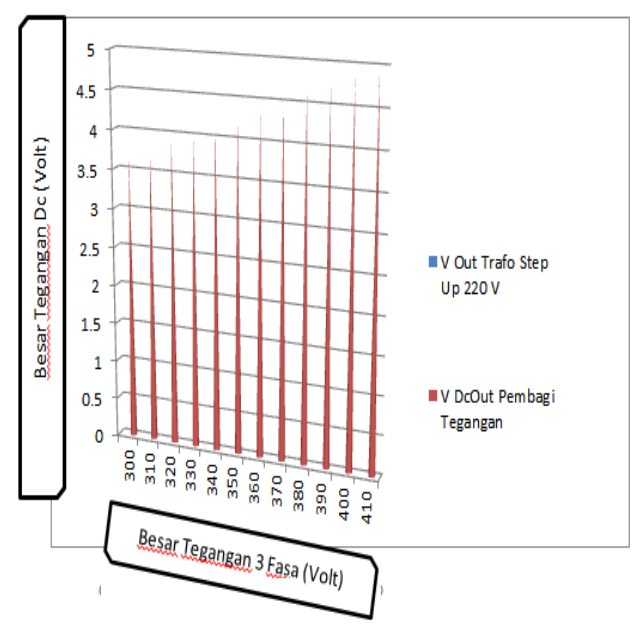

Gambar 4.2. Grafik Hasil Pengujian Sensor Tegangan

\subsection{Pengujian sistem keseluruhan}

Pada pengujian sistem keseluruhan dilakukan dengan menguji sistem alat terhadap perubahan kualitas daya yang terjadi pada tegangan tiga fasa. Dimana alat berfokus pada pengujian:

1. Tegangan Dip (Sag) yaitu dimana turunnya amplitudo tegangan rms dengan durasi waktu kurang dari 1 menit.

2. Swell adalah naiknya amplitudo tegangan rms dengan durasi waktu kurang dari 1 menit.

3. Undervoltage adalah turunnya amplitudo tegangan rms dalam waktu yang cukup lama (lebih dari 1 menit).

4. Overvoltage adalah naiknya amplitudo tegangan rms dalam cukup lama (lebih dari 1 menit).

Dalam sistem penyediaan tenaga listrik, secara umum tegangan listrik dititik suplai diijinkan bervariasi $(+5 \%)$ dan ($10 \%)$ sesuai standar PLN. Sedangkan dalam ANSI C 84.1 diijinkan (-10\%) dan (+ 4\%) dalam kondisi normal, lalu pada kondisi tertentu (darurat) diijinkan (-13\%) dan $(+6 \%)$. 
Nilai tegangan listrik untuk konsumen mengalami perubahan. Hal ini telah dinyatakan didalam Standar Perusahaan Listrik Negara (SPLN 1: 1995 Tegangan-tegangan Standar) yang menyebutkan bahwa tegangan nominal terminal APP (Alat Pembatas dan Pengukur) sebesar $220 \mathrm{~V} / 380 \mathrm{~V}$ diubah sesingkat mungkin sampai dengan tahun 2003 menjadi $230 \mathrm{~V} / 400 \mathrm{~V}$ dengan variasi tegangan $-10 \%$ sampai dengan $+5 \%$.

Misalnya, untuk sistem kelistrikan dengan tegangan $380 \mathrm{~V}$ akan dianggap normal bila:

$380 \mathrm{~V}-(380 \mathrm{~V} \times 10 \%) \leq$ tegangan standar $\leq 380 \mathrm{~V}+(380 \mathrm{~V} \times 5 \%)$ $342 \mathrm{~V} \leq$ tegangan standar $\leq 399 \mathrm{~V}$

Perhitungan di atas cukup menerangkan bahwa nilai tegangan antara $342 \mathrm{~V}$ sampai dengan $380 \mathrm{~V}$ adalah nilai tegangan yang dianggap normal. Oleh karena itu, dalam menggunakan semua peralatan listrik maupun elektronik, harus memperhatikan nilai tegangan kerja alat tersebut. Misalnya terdapat suatu alat elektronik dengan tegangan kerja sebesar $340 \mathrm{~V}$ sampai $390 \mathrm{~V}$. Hal ini berarti bahwa peralatan tersebut dapat diterapkan tegangan listrik sebesar $340 \mathrm{~V}$ sampai 390 V saja. Di luar nilai tersebut, tentunya akan merugikan atau membahayakan peralatan itu sendiri maupun penggunanya.

Dengan referensi yang ada maka dapat disimpulkan bahwa tegangan pengukuran tiga fasa yang terjadi dimana referensi tersebut untuk melihat perubahan kualitas daya yang terjadi pada instalasi listrik tiga fasa.

Gambar 4.3 berikut ini dapat dilihat sistem keseluruhan yang telah dibuat dan pengujiannya pada sistem tersebut.

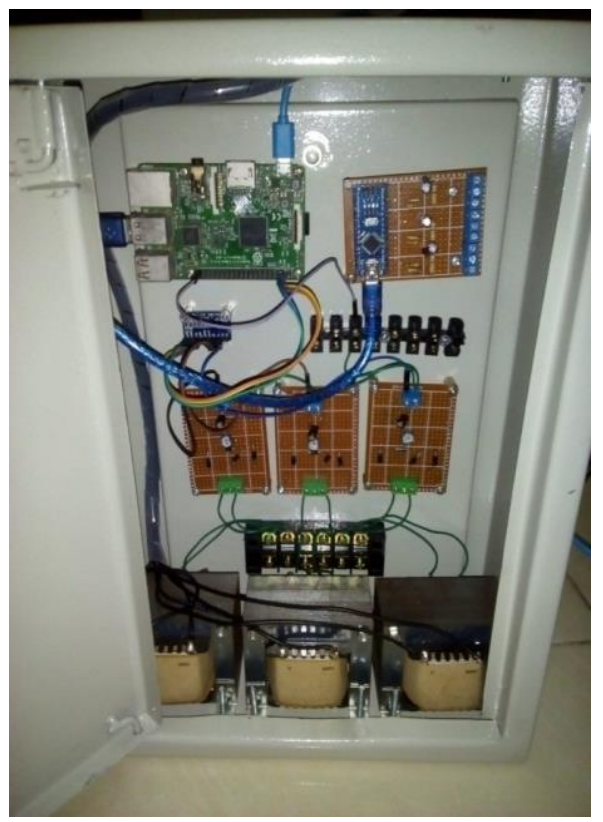

Gambar 4.3. Pengujian Sistem Keseluruhan

Hasil pengujian 3 fasa pada arus dan tegangan diperlihatkan dalam tabel 4.3 berikut dimana pengujian dilakukan sebanyak 10 kali.

Tabel 4.3. Data Hasil Pengujian Sistem Keseluruhan

\begin{tabular}{|c|c|c|c|c|c|c|c|c|}
\hline Pengu & \multicolumn{3}{|c|}{ Tegangan (volt) } & \multirow{2}{*}{$\begin{array}{l}\text { Rata- } \\
\text { rata } V\end{array}$} & \multicolumn{3}{|c|}{ Arus (Ampere) } & \multirow{2}{*}{$\begin{array}{l}\text { Rata- } \\
\text { rata I }\end{array}$} \\
\hline jian & $\mathrm{R}$ & $S$ & $\mathrm{~T}$ & & $\bar{R}$ & $S$ & $\mathrm{~T}$ & \\
\hline 1 & 378 & 380 & 369 & 375.6 & 11.4 & 11.6 & \begin{tabular}{|l}
11.7 \\
\end{tabular} & 11.5 \\
\hline 2 & 375 & 376 & 370 & 373.6 & 13.4 & 12.7 & 11.9 & 12.6 \\
\hline 3 & 377 & 370 & 372 & 373 & 12.4 & 12.3 & 11.9 & 12.2 \\
\hline 4 & 372 & 370 & \begin{tabular}{|l|}
373 \\
\end{tabular} & 371 & \begin{tabular}{|l}
11.4 \\
\end{tabular} & \begin{tabular}{|l|}
12.1 \\
\end{tabular} & 11.6 & \begin{tabular}{|l}
11.7 \\
\end{tabular} \\
\hline 5 & 370 & 373 & 373 & 372 & 11.2 & 11.3 & 11.2 & 11.2 \\
\hline 6 & 375 & 376 & 374 & 375 & 13.6 & \begin{tabular}{|l|}
12.7 \\
\end{tabular} & 14.2 & 13.5 \\
\hline 7 & 381 & 376 & 369 & 375.3 & 12.5 & \begin{tabular}{|l|}
13.1 \\
\end{tabular} & \begin{tabular}{|l|}
12.7 \\
\end{tabular} & \begin{tabular}{|l}
12.7 \\
\end{tabular} \\
\hline 8 & 378 & 374 & 369 & 373.6 & 13.5 & \begin{tabular}{|l|}
13.4 \\
\end{tabular} & 12.8 & 13.2 \\
\hline 9 & 374 & 375 & 368 & 372.3 & \begin{tabular}{|l}
12.8 \\
\end{tabular} & \begin{tabular}{|l}
13.7 \\
\end{tabular} & \begin{tabular}{|l}
14.2 \\
\end{tabular} & \begin{tabular}{|l}
13.5 \\
\end{tabular} \\
\hline 10 & 377 & 375 & 369 & 373.6 & 12.4 & 13.2 & 11.8 & 12.5 \\
\hline
\end{tabular}
tegangan:

Rata-rata 10 kali pengujian untuk

$(375.6+373.6+373+371+372+375+375.3+$ $373.6+372.3+373.6) / 10$ 


$$
=(3735) / 10
$$$$
=373.5 \mathrm{~V}
$$

Arus:

Rata-rata 10 kali pengujian untuk

$(11.5+12.6+12.2+11.7+11.2+13.5+12.7+1$

$$
3.2+13.5+12.5) / 10
$$

$=(124.6) / 10$

$=12.46 \mathrm{~A}$

Selanjutkan menentukan nilai error dimana dalam penelitian ini menggunakan metode menghitung standar deviasi dan standar error. Rumus standar deviasi adalah sebagai berikut dimana $X$ nilai ratarata RST tegangan/arus per pengujian, $\mu$ adalah nilai rata-rata tegangan/arus $10 \mathrm{kali}$ pengujian, $\mathrm{N}$ jumlah pengujian.

$$
\sigma=\sqrt{\frac{\sum(X-\mu)^{2}}{N}}
$$

Tabel 4.4. Standar deviasi pengujian Tegangan

\begin{tabular}{|c|c|c|c|c|}
\hline \multirow{2}{*}{$\begin{array}{c}\text { Pengujian } \\
\text { ke- }\end{array}$} & Vrata-rata RST & Vrata-rata 10 kali & & \\
\cline { 2 - 3 }$(\mathrm{X}$ & $\mathrm{X}$ & $\mu$ & \\
\hline 1 & 375.6 & 373.5 & 2.1 & $(\mathrm{X}-\mu)^{\wedge} 2$ \\
\hline 2 & 373.6 & 373.5 & 0.1 & 0.01 \\
\hline 3 & 373 & 373.5 & -0.5 & 0.25 \\
\hline 4 & 371 & 373.5 & -2.5 & 6.25 \\
\hline 5 & 372 & 373.5 & -1.5 & 2.25 \\
\hline 6 & 375 & 373.5 & 1.5 & 2.25 \\
\hline 7 & 375.3 & 373.5 & 1.8 & 3.24 \\
\hline 8 & 373.6 & 373.5 & 0.1 & 0.01 \\
\hline 9 & 372.3 & 373.5 & -1.2 & 1.44 \\
\hline 10 & 373.6 & 373.5 & 0.1 & 0.01 \\
\hline
\end{tabular}

Dari tabel diatas dilanjutkan perhitungannya sesuai rumus diatas sehingga didapatkan $\sigma=1.41845$

Setelah mendapatkan nilai standar deviasi, maka standar errornya adalah:

$S E=\frac{\sigma}{\sqrt{n}}$

Jadi SE $=1.41845 / \sqrt{10}$

$$
=0.45
$$

Menghitung nilai SE untuk data pengukuran arus dilakukan dengan rumus dan cara yang sama.

Tabel 4.5. Standar deviasi pengujian Arus

\begin{tabular}{|c|r|r|c|c|}
\hline \multirow{2}{*}{$\begin{array}{c}\text { Pengujian } \\
\text { ke- }\end{array}$} & I rata-rata RST & I rata-rata 10 kali & & \\
\cline { 2 - 3 } & $\mathrm{X}$ & $\mu$ & \multirow{2}{*}{$(\mathrm{X}-\mu)$} & $(\mathrm{X}-\mu)^{\wedge} 2$ \\
\hline 1 & 11.5 & 12.46 & -0.96 & 0.9216 \\
\hline 2 & 12.6 & 12.46 & 0.14 & 0.0196 \\
\hline 3 & 12.2 & 12.46 & -0.26 & 0.0676 \\
\hline 4 & 11.7 & 12.46 & -0.76 & 0.5776 \\
\hline 5 & 11.2 & 12.46 & -1.26 & 1.5876 \\
\hline 6 & 13.5 & 12.46 & 1.04 & 1.0816 \\
\hline 7 & 12.7 & 12.46 & 0.24 & 0.0576 \\
\hline 8 & 13.2 & 12.46 & 0.74 & 0.5476 \\
\hline 9 & 13.5 & 12.46 & 1.04 & 1.0816 \\
\hline 10 & 12.5 & 12.46 & 0.04 & 0.0016 \\
\hline
\end{tabular}

$\sigma=0.770973$

$\mathrm{SE}=0.24$

Dari hasil SE Tegangan dan SE Arus disimpulkan bahwa sistem mempunyai range keakuratan sebagaimana Standar IEC no. 13B-23. Klasifikasi alat ukur listrik menurut Standar IEC no. 13B23 menspesifikasikan bahwa ketelitian alat ukur dibagi menjadi 8 kelas, yaitu: 0.05; $0.1 ; 0.2 ; 0.5 ; 1.0 ; 1,5 ; 2,5$; dan 5 . Kelaskelas tersebut artinya bahwa besarnya kesalalahan dari alat ukur pada batas-batas ukur masing-masing yaitu $\pm 0.05 \%, \pm 0.1$ $\%, \pm 0.2 \%, \pm 0.5 \%, \pm 1.0 \%, \pm 1.5 \%, \pm 2.5$ $\%, \pm 5 \%$ dari relatif harga maksimum.

\subsection{Pengujian Pengiriman Data ke Website}

Data sensor dari Arduino yang diterima oleh raspberry pi kemudian diolah dan ditampilkan ke website. Raspberry dalam hal ini diprogram sebagai web server dengan mempunyai fungsi php didalamnya.

Berikut ini tampilan antar muka website pada gambar 4.4 dan 4.5 . 


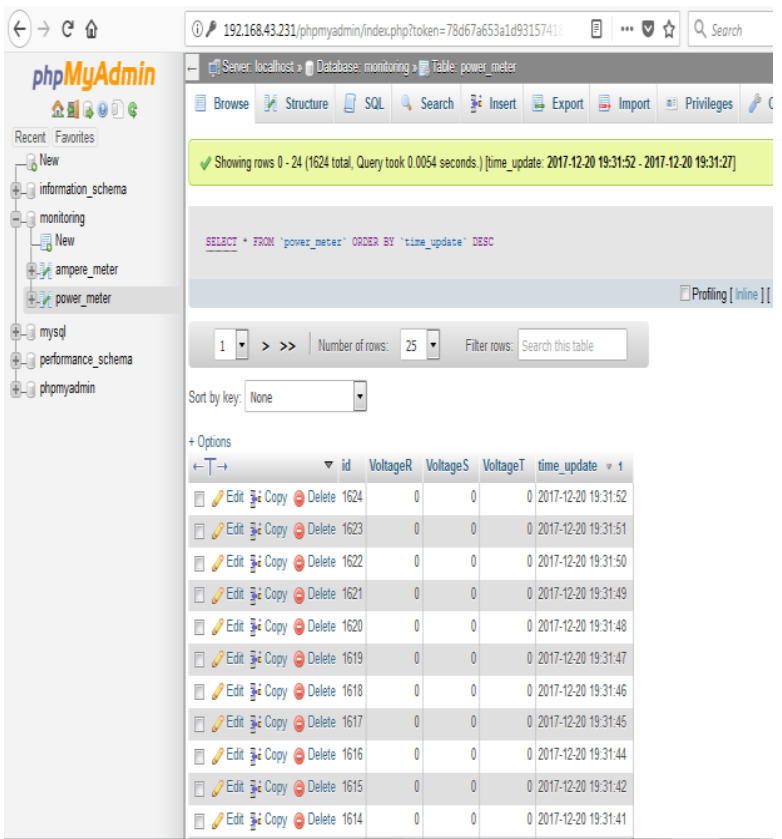

Gambar 4.4. Tampilan Php My Admin

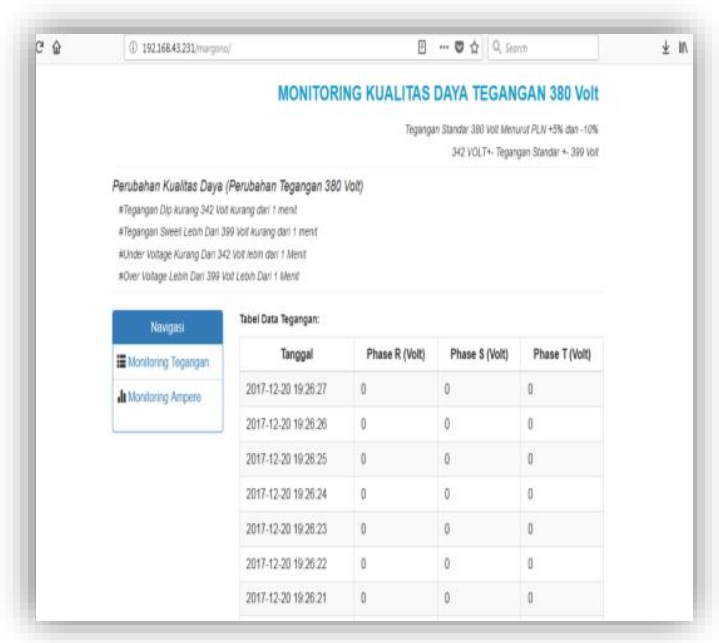

Gambar 4.5. Tampilan Pada Website

Dapat dilihat pada gambar diatas terdapat tabel pembacaan pengukuran kolom RST disesuaikan dengan monitor Arus atau Tegangan dalam waktu tertentu.

Pengujian akses website ini dilakukan dengan mengamati pembacaan dalam tabel website tersebut dimana hasil pengamatan bahwa website dapat menerima dari raspberry secara real time kira-kira 1 detik teramati dengan baik.

\section{KESIMPULAN}

Berdasarkan dari pengujian dan analisa dari Rancang Bangun Monitoring Kualitas Daya Dengan Raspberry, kesimpulannya sebagai berikut:

1. Sistem yang dibuat dapat melakukan pengukuran perubahan kualitas daya (tegangan yang tidak tetap) secara real time melalui antar muka antara Arduino dan raspberry dengan sensor dan ditampilkan dalam bentuk tabel dalam website.

2. Hasil pengujian sensor didapatkan nilai standar error untuk pengukuran tegangan 0.45 , dan pengukuran arus standar errornya 0.24. Hal ini menunjukkan bahwa alat ukur tegangan, dan alat ukur arus yang dibuat termasuk alat ukur presisi berdasarkan Standar IEC No. 13B-23.

3. Telah dibuat website dengan tampilan yang dapat menampilkan hasil dari sensor pengukur arus dan tegangan secara realtime dengan sampling rate kira-kira 1 data/detik.

\section{DAFTAR PUSTAKA}

[1] S Semwal, M Singh, RS Prasad .2015. Turkish Journal of Electrical journals.tubitak.gov.tr

[2] Á Asensio, Á Marco, dan R Blasco.2014. International Journal of, - journals. sagepub.com

[3] M Mallya. 2013. srimuthu. github.io

[4] Nurfaizzahbintibah Harin. 2015. portal.fke.utm. my/ fkelibrary /files

[5] AM Murcia, RB Ortega, dan IDF Lava. 2013. PA Vila, FF Gi - Waves, - riunet.upv.es

[6] IP Sudiarta, I Agung.2015. Jurnal Ilmiah Spektrum, - ojs.unud.ac.id

[7] Andi Setiawan. modul. mercubuana.ac.id.

[8] Stallings, William. 1996/0 1. Organisasi arsitektur 
mikrokomputer . Jakarta: Pt Prehanllindo

[9] andi Setiawan. Modul.

Mercubuana.ac.id

[10] McDaniel P,McLaughlin ,S. Security and privacy. 2009. challenges in the smart grid. IEEE Secur Priv.

[11] Santoso,H.(2012,Juni

MengenalIc Integrated circuit.

[12] Mohamad, N.b., Smart Meter for Domestic Devices. PSZ 19:16 Pind. 1/07, 2014.

[13] Febriadisantoso.weebly.com/knowle dge/embedded-system.

[14] Syahtmei. (2011, maret) IC Itegrated Circuit.

[15] John Catsoulis(2005). Embedded Sistem.

[16] Romy Budhi widodo. 2009.embedded system komputer \& pemprogaman c. Jakarta: andi publisher. 